\title{
Burden of the Care Givers of Mentally Retarded Children
}

\author{
K. Maheswari \\ Assistant Professor, Department of Social Work, Bharathidasan University College, \\ Perambalur, Tamilnadu.
}

\begin{abstract}
The disintegration of joint family system has made the family units smaller and the rate of marriage breakdown has increased. In the same period, with the technological advance in medicine, the survival of children with disabilities has risen. It has been estimated that about 10 per cent of children experience developmental disorders requiring access to the health care system and extensive care giving, often throughout childhood and into the adult years. Community-based care settings may serve to increase demands on family members, it is essential to be more active participants in the care of their child. This present study was carried out to assess the burden experienced by the care givers of disabled children. Purposive sampling method was adopted to collect data from 50 respondents. Descriptive research design was used and the results indicated that less than half of the respondents (44\%) have high level of burden and majority of the care givers are female.
\end{abstract}

Keywords: Burden, Care Giving, Disabled, Mentally retarded

\section{Introduction}

Mental health problems affect all societies as a whole. It is said that 450 million people suffer from a mental or behavioral disorder and nearly I million people suicide every year (WHO, 2003). The treatment and rehabilitation of clients with mental illness are regarded as a heavy burden for every government and family. Raising a child who is mentally challenged requires emotional strength and flexibility. The child has special needs in addition to the regular needs of all children and care givers can find themselves overwhelmed by various medical care giving and educational responsibilities. Whether special needs of the child are minimal or complex, the care givers lack support from family, friends, community or paid care givers and is critical to maintain balance in the home. So in this present scenario, it is significant to study the care giving burden experienced by the care givers of disabled children and this has paved way to gain in-depth knowledge about care giving and mental retardation among the social workers working in different settings. Caregiver burden is a term used to describe the physical, emotional and financial duty of providing care to the needy.

Parental care for a child with a developmental disability is an enormous responsibility, one that can far exceed that of typical parental care. While most care givers adapt well to the situation of caring for a child with a disability and some do not. To understand parent's adaptations to their children's disabilities, the complex nature of burnout must be accounted for and the constructs and factors that play a role in the care giving must be considered. The attitudes and emotional reaction of care givers of disabled children are of crucial importance in planning for their treatment and rehabilitation. It is found that $71 \%$ of the mothers do felt scared when they realized that their child is retarded. Some care givers do not admit that they have a deficit child and label against it and keep the child behind closed doors for fear of criticism from others. Because a lack of understanding about the family member's disease process may worsen caregiver stress, the caregiver's knowledge about the illness and available resources should be explored and additional information provided when needed (Burnett and Meares, 2000).

\section{Review of Literature}

Shyam etal (2014) conducted a study on parenting stress and family burden in mothers of children with disabilities and children without disability. Parenting stress index and family burden scale were administered on 125 mothers of children with disabilities and without disability (25mothers in each group), selected from three districts of Haryana state. The major findings revealed that mothers of children with both mental and physical disability and mothers of children with mental disability scored significantly higher level of parenting stress and family burden compared to mothers of children with physical disability, mothers of deaf and dumb children, and mothers of children without disability. Beckman (2004) compared mothers and father's perception of the effect of young children with and without disabilities (moderately and severely delayed). Results indicated significant differences between mothers and fathers on parent domain of the parental stress index. Mothers reported more stress than the fathers. Parent of children with disabilities report more care-giving requirements and stress in all domains. Stress was negatively associated with informal support for both care 
givers and positively associated with increased care giving requirements for mothers. Al-Kuwari (2007) revealed that mothers of mentally disabled children have poorer psychological health than mothers of nondisabled children. Shifting the rehabilitation services from child-centered to family- centered services through providing supportive services is recommended. Sethi et al (2007) studied the level of stress and burden in the caregivers of children with mental retardation and analyzed the differences in various socio-demographic characteristics. No significant difference was noticed between the 3 groups as a whole as well as when mothers and fathers were compared amongst themselves for age, educational level and income of family. $41 \%$ of the carer's were illiterate. They also revealed that most mothers were home-makers and the fathers were farmers or laborers. $52 \%$ belonged to the nuclear families and nearly 15 hours per day was spent significantly by the mothers for caring the disabled children than their spouses. Talley and Crews, (2007) indicated that caregivers require supportive services for their care giving tasks and good health status is needed to provide better care for the needy. Care givers who are younger may experience a significant protective factor in the care giving to a young child, despite the stresses and adjustments experienced to the family. However, in most countries, people are living longer, including those who are living with chronic illnesses and disabilities. As the seriously disabled child ages, the entire family system ages and this may call for additional forms of care giving support services to meet the challenges of the aging family.

Aim

The aim of the study is to assess the burden experienced by the care givers of mentally retarded children.

\section{Objectives}

- To study the socio-demographic characteristics of the respondents.

- To assess the level of burden experienced by the respondents.

- To find out the association between the selected socio-demographic variables and the key variable.

\section{Research Design}

In the present study the researcher has attempted to investigate the level of care giving burden experienced by the care givers of disabled children. The effort of the investigation is to provide a descriptive profile of the respondents. Further the researcher has attempted to find out the association between the various variables of the study. Hence for this study descriptive research design was adopted.

\section{Universe}

The researcher had collected data from the care givers of disabled children registered under the Integrated Education for Disabled children scheme of SEVAI and SOC-SEAD (Non-Governmental Organizations) at Trichy. The universe of the present study includes the care givers of disabled children (especially mentally retarded) who are benefitted by the day care centers functioning under the above mentioned NGOs.

\section{Sampling}

The researcher has adopted purposive sampling method to collect data from the care givers of mentally retarded children in Trichy. The sample size is 50.

\section{Tools of Data Collection}

- $\quad$ Self prepared interview schedule pertaining to socio- demographic characteristics which included 15 items was used.

- $\quad$ Zarit Care Giving Burden scale (2000) developed by Park et al was used to assess the burden experienced by the care givers of mentally retarded children.

\section{Statistical Analysis}

Frequencies and cross tabulations were done in the study to check the distribution of the key variable across socio-economic variables. Chi-square test was used to check the association between the selected socio demographic variables and care giving burden of the respondents. Statistical analysis of data was carried with the help of SPSS package.

\section{Results}

The findings of the study reveal that less than half of the respondents (44\%) are between 31 and 40 years of age and great majority of the respondents $(88 \%)$ were female and the remaining per cent were male and especially fathers. Most of the surveyed respondents were Hindus. It is also noted that forty per cent of the respondents had consanguinity marriage. Majority of them are educated up to school level $\left(10^{\text {th }}\right.$ and $\left.12^{\text {th }}\right)$. 
Among the surveyed respondents 42 per cent of them are doing private jobs and remaining 58 per cent are not working and they are home makers, grandmothers and care takers. Nearly half of the respondents had borrowed money to meet out the household expenses and treatments. The respondents used to borrow money from their neighbours, relatives, and mortgage their jewels and some get money from the money lenders for their urgent needs. Majority of the respondents are living in nuclear families and so it is difficult for them to get all sort of support from their in-laws.

With regard to the care givers, majority of the respondents (68\%) are mothers, followed by 28 per cent are grandmothers and the remaining 4 percent are fathers. It is also observed that majority of the respondents children are moderately disabled and majority of their children $(56 \%)$ have the disability from birth. To understand whether the respondents children were benefitted from any government schemes, information's were gathered regarding the scheme availed and it was found that great majority $(85 \%)$ of them receive the stipend of Rs. 1000/- given by the government to the children as well as care takers, have got the equipments, and access to day care centers for their children with special needs.

Regarding the burden experienced by the respondents, 44 per cent of them had said that they experience high level of burden in taking care of the mentally retarded children and burden is experienced on various aspects such as poor financial support, lack of accessibility, poor usage of appliances, lack of knowledge and understanding about mental retardation, lack of family members support, poor skill in disability management, physical health deterioration of care takers is also a major reason for burden because they spend most of their time in care taking of special children and also look after other family members.

It is evident from the study that there is a significant association between the age of the respondents' children and benefit received from the government. It can be said that early identification of the disability will lead to better usage of the government services on various dimensions such as economic support, appliances, accessibility, education, health services, treatment and rehabilitation. It is also evident from the study that there were no significant associations between the socio demographic variables such as age, education, religion, family type, marital status and care giving burden of the respondents. However, there was a significant association between the respondents' income and burden of care giving. Majority of the respondents are poor and they do not have other sources of income other than their monthly income to take care of their special children with special needs. It is a known fact that income is the ultimate need of all families to fulfill their basic needs as well as special needs.

\section{Conclusion}

Family is the prime support system for the persons with disabilities in any society. Families experience economic, physical and emotional burden while caring the disabled persons. Awareness about disability and its management must be created among the community in general and to mothers in particular because most of the care takers are mothers. Knowledge about welfare measures and rehabilitative measures must be disseminated among the public in regular intervals, so that care givers will be a position to take care of their special children with care and support. It is also insisted that the care givers must also think about their psychosocial conditions and must take considerable care. Well targeted treatment measures and prevention programmes will definitely pave way for better living of the people with disability and also increases their longevity.

\section{References}

[1]. Radhey Shyam., Kavita and Deepika Govil., (2014) Stress and Family Burden in Mothers of Children with Disabilities. International Journal of Interdisciplinary and Multidisciplinary Studies Vol 1, No.4, 152-159.

[2]. Al-Kuwari MG., (2007)Psychological health of mothers caring for mentally disabled children in Qatar. Neurosciences (Riyadh). Oct;12(4):312-7.

[3]. Burnett, S.A., and Meares., P.A. (2000). Infants and toddlers with disabilities:

[4]. Relationship- Based Approaches. Social Work, 45,371-380.

[5]. Sujata Sethi, Subhash C. Bhargava, Vishal Dhiman (2007). Study of level of stress and burden in the caregivers of children with mental retardation. Eastern Journal of Medicine Vol.12, pp 21-24.

[6]. Talley, R. C., \& Crews, J. E. (2007). Framing the public health of care giving. American Journal of Public Health, 97(2), $224-228$.

[7]. WHO Report on Mental Health, 2003. 